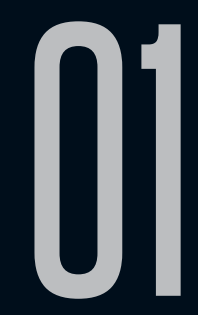

\title{
DÉCADENCE FIN DE SIÈCLE (2017), DE MICHEL WINOCK
}

Daniel Augusto P. Silva (UERJ/CAPES) ${ }^{1}$

Recebido em 18 mai 2019. Daniel Augusto P. Silva é Doutorando em Teoria da Aprovado em 28 jun 2019. Literatura e Literatura Comparada na Universidade do Estado do Rio de Janeiro e bolsista CAPES sob orientação do Prof. Dr. Julio França (UERJ). Além disso, integra o Grupo de Pesquisa Estudos do Gótico (CNPq). É coorganizador do livro Páginas Perversas: narrativas brasileiras esquecidas (Appris, 2017).

10 presente trabalho foi realizado com apoio da Coordenação de Aperfeiçoamento de Pessoal de Nível Superior - Brasil (CAPES) - Código de Financiamento 001. 
O historiador Michel Winock é autor de uma obra acadêmica bastante diversificada, reconhecida e premiada. Além de ter estudado tópicos do desenvolvimento político francês e de ter produzido biografias sobre Gustave Flaubert e Madame de Staël, ele se tornou particularmente conhecido pelo livro O Século dos intelectuais [1997], em que se dedica a analisar a atuação

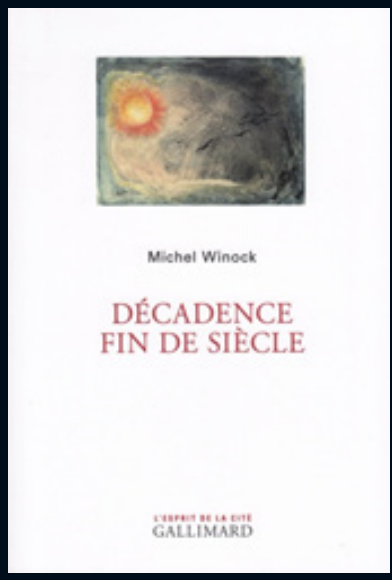
de intelectuais franceses, como André Gide e Jean-Paul Sartre, no século XX. Recentemente, em outubro de 2017, o acadêmico publicou, pela editora Gallimard, o volume Décadence Fin de Siècle, ainda sem tradução para o português. Na obra, ele analisa a produção artística e as ideias culturais, políticas e sociais das últimas décadas do século XIX. Trata-se não apenas de um período fértil para a literatura francesa, mas também de interesse para os pesquisadores do insólito ficcional, pois é quando surge a prosa de ficção decadente, caracterizada por uma abordagem negativa, pessimista e, em geral, não mimética da realidade. Dividido em dezessete capítulos, o trabalho apresenta elementos do imaginário de escritores como Léon Bloy, Joris-Karl Huysmans, Joséphin Péladan, Rachilde, Maurice Barrès, Barbey d’Aurevilly, e temas variados, como a decadência, o satanismo, o ocultismo, a androginia, a morbidez, o anarquismo e o nacionalismo.

No prefácio do volume, Winock justifica seu interesse pelos anos finais dos Oitocentos e aponta para a relevância em estudá-los. A primeira razão tem como base a própria trajetória do pesquisador, 
que ainda não havia publicado uma obra especificamente voltada para essa época. Após ter se interessado pela intelectualidade francesa do século $X X$ e por personalidades ativas nos debates políticos entre 1789 e 1885, como Victor Hugo, faltava-lhe um trabalho mais detido sobre as figuras de destaque para a história das ideias entre esses dois recortes temporais. A segunda diz respeito à identificação de uma base comum ao pensamento francês finissecular: a ideia de decadência. Em termos literários, Winock (2017, p.10) destaca a influência de Baudelaire para diversos autores dessa geração, que teriam dado forma à concepção de "uma modernidade mórbida, na qual triunfam a putrefação, a decomposição de uma sociedade infectada de vícios" ${ }^{\prime 2}$. Assim, se busca definir quais foram as causas e as consequências políticas, sociais e artísticas desse sentimento de degeneração apontado por diversos escritores.

O primeiro capítulo do livro, intitulado "República e Decadência", aponta para um aparente paradoxo do final do século XIX: embora seja um período de significativos avanços técnicocientífico e de melhorias na qualidade de vida da população, um sem-número de intelectuais e artistas expressava um sentimento de profunda desilusão e uma impressão de decadência da sociedade. Winock (2017, p.13) indica a possibilidade de interpretar as duas últimas décadas oitocentistas tanto como o triunfo e como o fortalecimento da República, com sucessivas leis sobre liberdade de imprensa, de organização sindical e de divórcio, quanto como o de uma grande depressão social, política e cultural. 
Haveria também argumentos para justificar uma compreensão mais negativa da realidade francesa. Um deles seria a situação demográfica do país, que tinha o menor ritmo de crescimento populacional se comparado a outros países europeus, em especial à Alemanha. Além da baixa taxa de fecundidade dos franceses, a economia passava por um período negativo, com balança comercial deficitária, com aumento nas taxas de desemprego e com dificuldades na produção agrária.

A percepção da decadência da sociedade estaria baseada, sobretudo, em um terceiro aspecto: a progressiva laicização da França. Como aponta Winock (2017, p.16), a instauração da República francesa ocorreu a partir de disputas com a Igreja católica, que se aliava a grupos monarquistas. Com o regime republicano, conventos são fechados, religiosos são expulsos de instituições educacionais e leis pela laicização do ensino são aprovadas. Os novos programas escolares se baseiam em uma separação entre os valores religiosos católicos e os conteúdos científicos e históricos. A essas medidas institucionais alia-se a percepção de que os próprios hábitos culturais haviam passado por uma progressiva distanciação em relação aos dogmas cristãos. Contra esse contexto colocavamse escritores católicos e outros futuramente convertidos, como Barbey d'Aurevilly, León Bloy, Huysmans, Claudel e Bourget. Em momentos diferentes de suas carreiras, eles indicaram a perda de valores religiosos e o materialismo como algumas das causas do estado de degradação social e de pessimismo generalizado.

Se a alma estava doente, afastada dos princípios religiosos, também o corpo sentiria os efeitos da decadência. Uma das principais ameaças à saúde dos franceses do período era o contágio 
pela sífilis, cujos efeitos poderiam deformar severamente o físico dos doentes. Nesse contexto, as práticas sexuais são colocadas sob o exame das ciências e da medicina, que buscavam determinar quais delas seriam as sadias e as potencialmente degradantes. Nas artes, a obsessão com as doenças sexualmente transmissíveis encontraria representação em figuras femininas simultaneamente mórbidas e atraentes, como as femmes fatales (WINOCK, 2017, p.22). Associada ao lento crescimento demográfico, aos problemas econômicos, à laicização do sistema educacional do país, à degradação física da população e à expansão do sistema democrático, a decadência se tornou uma noção abrangente e bastante útil para caracterizar a visão de mundo desencantada de parte significativa da intelectualidade do período:

Decadência? Melhor seria, na verdade, empregar o plural, de tanto que a decadência carrega todos os fantasmas. Ela cobre com seu manto generoso todos os medos de dissolução, de decomposição, de perda de unidade, de colapso de valores. A ideia da igualdade, que subentende também a emancipação da mulher, ameaça explodir a família. Enquanto a obsessão dos maus costumes ocupa o coração do pensamento decadencial: a droga, o adultério, o onanismo, a prostituição, a homossexualidade, a efeminação dos homens e a virilização das mulheres aparecem como sintomas de uma degenerescência física dos franceses (WINOCK, 2017, p.21)

Winock (2017, p.23) indica, brevemente, como o termo "decadente" foi utilizado como alcunha por grupos de escritores que se colocavam contra o naturalismo. Embora tal fenômeno seja verificável em diversas publicações, é preciso destacar o quanto a 
decadência literária e a ficção naturalismo compartilharam temas, técnicas discursivas e recursos narrativos. De todo modo, para exemplificar sua afirmação anterior, o historiador menciona a criação da revista Le Décadent, em 1886, sob a direção do poeta Anatole Baju, que contou com colaborações de autores como Stéphane Mallarmé e Jean Lorrain, entre tantos outros. Nesse tipo de publicação, os autores desenvolveriam um tipo de estilo específico, marcado por termos raros, neologismos e desvios sintáticos, de modo a destacar o caráter artificial, criativo e original de suas produções, distantes do prosaísmo do cotidiano e de parte da literatura popular.

Na parte conclusiva a tais reflexões, Winock $(2017$, p.24) comenta, ainda, que "no final dos anos 1880, o movimento simbolista veio a absorver os adeptos da escola decadente [...]". Nessa afirmação, identificamos duas concepções falhas sobre a decadência literária. A primeira diz respeito à concepção, provavelmente baseada nos estudos de Guy Michaud [1947], segundo a qual a decadência serviria como uma espécie de primeira fase para o desenvolvimento da poesia simbolista, que seria responsável por depurar a arte decadente. A segunda afirmação questionável do autor é sobre a existência de uma "escola decadente". Atualmente, é amplamente defendido pelos estudiosos da literatura fin-de-siècle que não houve uma constituição de um movimento decadente bem definido e com preceitos artísticos amplamente compartilhados e defendidos. Consequentemente, tais estudiosos comentam como as fronteiras eram os chamados "decadentes" e os "simbolistas" eram difíceis de traçar com exatidão.

Nos capítulos subsequentes, o historiador examina ora a produção de romancistas específicos ora alguns temas, tanto 
sociais quanto artísticos, do contexto finissecular e do imaginário decadente. O primeiro escritor apresentado é Léon Bloy (1846-1917), cuja trajetória como obstinado defensor dos princípios católicos é explicitada em detalhes. Embora também mencione o trabalho ficcional do autor, Winock (2017, p.29) enfatiza, em especial, os seus textos jornalísticos, nos quais propagava uma série de críticas contra o anticlericalismo e o materialismo de seus pares. A partir de diversos dados biográficos, o leitor também é informado sobre a atuação dos grupos de intelectuais cristãos frequentados pelo autor, bem como sobre os conflitos gerados por seu comportamento combativo e dogmático. Ao denunciar uma sociedade distante de valores edificantes e marcada pela corrupção moral, parte das narrativas de Bloy compõe o grupo de escritos decadentes da época.

Entre as outras obras decadentes apontadas no volume, À rebours (1884), de Joris-Karl Huysmans (1848-1907), é considerado o lançamento literário mais importante de seu ano de publicação. Após indicar a originalidade do romance e classificá-lo como sem precedentes na literatura francesa, Winock (2017, p.40) qualifica-o como uma espécie de "romance-farol", em virtude de sua repercussão nas letras e de sua centralidade para as reflexões sobre a decadência. Com uma estrutura narrativa quase sem peripécias e com capítulos que podem ser lidos em uma ordem não linear, o livro desenvolve os gostos artísticos excêntricos, as nevroses e o comportamento mórbido de seu protagonista, o aristocrata e esteta Des Esseintes. Ao ressaltar a artificialidade como princípio artístico, em oposição às criações da natureza, e ao se afastar de temas e de personagens prosaicos, o livro indicaria uma nova via ficcional em relação ao naturalismo, ao qual Huysmans se filiara até então. 
Apesar de ter alcançado um significativo número de vendas e elogios da imprensa e de escritores, como Remy de Gourmont e Barbey d'Aurevilly, o romance recebeu críticas negativas em relação ao seu estilo discursivo, considerado extravagante, alambicado e excessivamente artificial. Com efeito, um dos principais traços da literatura fin-de-siècle, tanto na poesia quanto na prosa, foi um uso específico da linguagem, repleta de termos raros, neologismos, inversões sintáticas e de desvios gramaticais. Nesse contexto, a decadência é percebida não apenas a nível narrativo e temático, mas também a nível textual, já que visaria, não raras vezes, ao hermetismo e à obscuridade semântica, o que foi considerado como uma corrupção da língua francesa. De todo modo, tais características exerceram uma influência significativa sobre toda uma geração de escritores, como comenta Winock (2017, p.49): "Para muitos, À rebours havia dado o sinal de uma grande virada literária".

O ano de 1884 teve, ainda, mais uma publicação importante para a constituição da ficção decadente: a edição de Le Vice suprême, de Joséphin Péladan (1858-1918). Com suas obras, o autor seria o representante, por excelência, de um dos aspectos estruturantes da decadência: a exploração do ocultismo. Com o desenvolvimento de personagens descritos como magos, capazes de se comunicar com espíritos e de fazer previsões, Péladan "pretendia alcançar o conhecimento do invisível, do incognoscível, do mistério, do sobrenatural" (WINOCK, 2017, p.65). Frequentemente, nos diálogos empreendidos por tais figuras, surgem críticas ao materialismo, ao cientificismo e ao desprezo à noção de alma. Sob esse ponto de vista, não seria mais possível tratar da humanidade apenas em seus aspectos instintivos e biológicos. Variadas e bastante comentadas nos 
periódicos, as diversas correntes místicas e espiritualistas do final do século XIX também levaram à tematização do satanismo, recorrente na ficção decadente, como atesta, por exemplo, o romance Là-bas (1891), de Huysmans, com suas cenas de missas negras.

Aos cultos satânicos aliava-se, sistematicamente, uma concepção degradante e transgressiva da sexualidade. No quinto capítulo de sua obra, Winock (2017, p.67) busca analisar como a ficção decadente representou as práticas sexuais, que, nos romances, surgiam como uma "obsessão fixada sobre o estranho, o bizarro, o mórbido, o pútrido e o perverso, da impotência de amar ao incesto, do deleite sádico à orgia platônica, da devassidão refinada à guerra dos sexos". Além dos autores já citados anteriormente, tais traços são bastante verificáveis nos romances de Jean Lorrain e de Rachilde, que ainda engendraram personagens andróginos, homossexuais, masoquistas e obcecados com orgias. Na decadência, associa-se ao desejo sexual a percepção de decrepitude física e moral, sobretudo nas figuras das femmes fatales. Vetores de doenças sexualmente transmissíveis, como a sífilis, essas mulheres, simultaneamente atraentes e repulsivas, constituem um dos arquétipos mais comuns da ficção decadente.

Ao tratar de conteúdos macabros e de personagens doentios, a decadência literária explicita a sua atração pelo mal, cujas figurações seriam capazes de impactar e de chocar a recepção. Winock (2017, p.10) defende que essa tendência teria uma de suas mais produtivas fontes na obra de Barbey d'Aurevilly (18081889), cujo "grande tema é o Mal". Embora fosse mais velho que os demais escritores associados à arte decadente, ele teria conseguido exercer grande influência no meio literário, tanto em razão de seus 
livros quanto por sua relação pessoal com autores como Léon Bloy, Joséphin Péladan e Jean Richepin. Sua obra mais célebre e uma das referências intertextuais para a decadência literária, Les Diaboliques (1874) revelava justamente uma poética voltada para o disforme, para personagens monstruosas e para comportamentos transgressivos. Ao publicar o volume, um conjunto de seis narrativas, o escritor foi formalmente acusado de ultrajar a moral pública. Além de compartilhar uma visão artística semelhante a de muitos autores da decadência, ele também era católico e, nesse período, defendia ideias monarquistas. Esse conjunto de características, tanto pessoais quanto estéticas, tornou-o, "nesse fim de século, um dos ícones de resistência à modernidade" (WINOCK, 2017, p.143).

Não apenas as questões religiosas pautavam os debates intelectuais nesse final de século e geravam interpretações negativas sobre o futuro do país. Diversos outros temas, sobretudo os de cunho político e social, acirravam os ânimos na França. Entre eles, destacamse os atentados anarquistas, o desenvolvimento do socialismo e do movimento operário, o fortalecimento do nacionalismo, as tensões antissemitas e as polêmicas sobre a criação da Torre Eiffel para a Exposição universal de 1889. Pelo menos sete capítulos do livro de Winock são dedicados a analisar esses eventos, marcados igualmente pela percepção de decadência. Alguns escritores se engajaram em diversos desses tópicos e também enveredaram pela carreira política. Maurice Barrès (1862-1923), por exemplo, foi eleito deputado e se tornou uma figura de relevo no discurso nacionalista. Já em outro espectro ideológico e com severas críticas ao sistema eleitoral, Octave Mirbeau (1848-1917) se notabilizou por seu apoio aos anarquistas. O descontentamento com o estado de coisas na 
França não apenas impulsionou esses autores à atuação política, como também propiciou que produzissem obras decadentes.

A percepção de decadência seria impulsionada, ainda, por um dos eventos mais marcantes do final do século XIX: o incêndio do Bazar de la Charité, em 4 de maio de 1897, com aproximadamente 120 mortos. No local, acontecia, anualmente, um encontro, em que instituições de caridade, formadas pela alta sociedade católica, vendiam uma série de produtos a fim de arrecadar fundos para doações aos mais pobres. A comoção gerada pelo incidente foi influenciada, em especial, pelo perfil das vítimas, pois, em sua maioria, eram mulheres da aristocracia e da alta burguesia, que professavam a fé católica. As reações à notícia foram exaltadas: muitos teriam encarado a tragédia como um sinal divino de que a França estaria se afastando do bom caminho da religião. Com explicações diversas, mas, majoritariamente, ligadas a uma constatação de debacle coletiva, os jornais também exploraram em detalhes o caso, com dados minuciosos sobre o estado dos cadáveres. Ao comentar a cobertura sensacionalista da imprensa sobre as mortes, Winock (2017, p.257) entende a morbidez como um dos principais aspectos do Zeitgeist finissecular: "Este fim de século é, com efeito, sádico. Sua literatura e sua arte se comprazem nos espetáculos de horror, nas cenas frenéticas, na descrição de perversões raras, no gosto do sacrilégio".

No epílogo de sua obra, o historiador sugere que o sentimento de decadência do final dos Oitocentos se prolongou até o início do século XX. Mesmo com a retomada da economia francesa nos últimos anos da década de 1890, que viria a ser nomeado como o início de uma Belle Époque, o agravamento das ideias nacionalistas 
e do antissemitismo continuariam a promover um sentimento de nostalgia em relação a um suposto passado glorioso, quando tudo era melhor. O desenvolvimento dessas ideias, como sabemos, culminou na Primeira Guerra Mundial. Nesse sentido, parte dos questionamentos do contexto finissecular e o seu intenso pessimismo não se encerram com a mudança de século:

[U]ma mentalidade coletiva - seja ela impulsionada por um meio restrito - é um fato histórico tanto quanto uma guerra ou um golpe de estado. O fim do século XIX, sem dúvidas, banhou-se em um pessimismo sepulcral, cuja dimensão, é verdade, continua imprecisa, por falta de pesquisas de opinião. O tom é dado pelos homens de letras, nos jornais como nos livros; é o tom da época (WINOCK, 2017, p.256)

Ao organizar as ideias de alguns dos principais intelectuais e artistas do final do século XIX, Michel Winock demonstra como esse foi um período bastante produtivo e relevante tanto do ponto de vista do debate de ideias quanto da produção ficcional. Além disso, sua obra tem o mérito de divulgar, em uma linguagem acessível e de forma concisa, os principais aspectos e temáticas da mentalidade fin-de-siècle. O conhecimento do historiador nas minúcias da política e das disputas sociais do período é, ainda, um ponto de destaque do volume, capaz de lançar luzes sobre alguns dos ideais presentes nas obras literárias. Embora não apresente uma abordagem particularmente original em relação às realizações literárias nem grande número de dados inéditos, trata-se de um livro relevante para quem deseja entender como a ideia de decadência estruturou o pensamento do período e deu forma a uma poética específica, com conteúdos, figuras, enredos e estilos discursivos identificáveis. 
Para os pesquisadores das diversas vertentes da ficção insólita, Décadence Fin de Siècle revela uma das literaturas mais pessimistas, desencantadas e mórbidas da ficção ocidental, responsável por desenvolver arquétipos e temas bastante duradouros e influentes em diversas literaturas nacionais.

\section{REFERÊNCIAS}

WINOCK, Michel (2017). Décadence Fin de Siècle. Paris: Gallimard. 